\title{
The Reaction between Histidine and Formaldehyde
}

\author{
By A. NEUBERGER, National Institute for Medical Research, London, N.W. 3
}

(Received 7 July 1944)

The reaction between formaldehyde and aminoacids occurs in two distinct stages (Wadsworth \& Pangborn, 1936). The first stage is a reversible reaction between the carbonyl and amino groups leading to compounds of an aldimine or $N$-methylol structure which dissociate readily into the original components. This reaction has been extensively studied by potentiometric and polarimetric methods. The second phase consists of reactions which are irreversible in most cases and the nature of which varies for different amino-acids. This second reaction is very slow in some cases, e.g. with glutamic acid where no reaction products have so far been isolated; in others it is, however, quite fast, as with asparagine which leads to a hexahydropyrimidine derivative (Schiff, 1900; Lovy \& Silbermann, 1937).

The reaction between histidine and formaldehyde has been investigated by several workers. Birch \& Harris (1930) and Levy (1935a) have studied the reaction potentiometrically and interpreted their results in terms of a reversible association of form. aldehyde and the amino-acid; the latter author assumed that only the $\alpha$-amino group was involved. Frieden, Dunn \& Coryell (1943), who used a polarimetric method, also considered the reaction to be reversible. That such an assumption, however, is incorrect had already been shown by Holden \& Freemen (1931), who demonstrated that, if histidine is incubated with about $2.5 \mathrm{~mol}$. of formaldehyde at $37^{\circ}$, most of the $\alpha$-amino-N, as measured by the Van Slyke method, is lost in the first few minutes. These authors also noticed that an insoluble product crystallized from the reaction mixture; this compound was not further investigated. Tire very fast, irreversible reaction of histidine was later confirmed by Wadsworth \& Pangborn (1936). The present paper deals with the structure of the compounds formed, their dissociation constants and the mechanism of the reaction.

If histidine is incubated at $37^{\circ}$ with two or more mol. of formaldehyde, a very insoluble compound $(A)$ is formed which contains two more carbon atoms than histidine. This compound dissociates on heating or on acidification, and splits off one mol. of formaldehyde. A new stable compound $(B)$ is formed which contains only one carbon atom more than histidine. Compound $B$ can also be obtained by incubating histidine with exactly one mol. formaldehyde, or by treatment of histidine with methylal and conc. $\mathrm{HCl}$ at $100^{\circ}$ (Wellisch, 1913). On addition of one mol. of formaldehyde, com. pound $B$ is converted almost instantaneously into compound $A$. These reactions and analysis show that compounds $A$ and $B$ have the same fundamental structure and compound $A$ is only an $N$. methylol derivative of $B$.

Compound $B$ gives a negative ninhydrin reaction and does not react with nitrous acid with evolution of gas. Analysis indicates that its formula is $\mathrm{C}_{7} \mathrm{H}_{9} \mathrm{O}_{2} \mathrm{~N}_{8}$. It appears, therefore, that a new ring has been formed involving both the $\alpha$-amino group and the iminazole nucleus. The new ring could have either a tetrahydropyridine structure (I), formed by interaction with $C_{d}$ of the iminazole nucleus or a hexahydropyrimidine structure (II) involving the imino-group $\left(\mathrm{N}_{1}\right)$. Formation of a seven-membered ring by combination with the $\mathrm{C}_{2}$ seems unlikely. The stability of $B$ to acid and alkali appears to exclude a hexhydropyrimidine structure, since fully reduced pyrimidines are very easily hydrolyzed by acid (Titherley \& Branch, 1913). Both $A$ and $B$ give positive Pauly reactions; this reaction is not given by $\mathrm{N}$-substituted iminazoles (Burian, 1904), whilst 4:5-disubstituted derivatives give a positive reaction (Fargher \& Pyman, 1919). The positive Pauly reaction is, therefore, in accordance with structure (I).

More direct evidence was, however, obtained in the following way: $B$ was decarboxylated, though in bad yield, at $265^{\circ}$ in fluorene (Waser, 1925) to a base (III) which was found to be,identical with a compound obtained by condensation of histamine with methylal (Fraenkel \& Zeimer, 1920; Dale \& Dudley, 1921). This base, on benzoylation, gave formic acid and a crystalline compound which analyzed correctly for a tribenzoyl derivative of diamino-tetrahydropyridine (IV). The formation of a tribenzoyl compound indicates that a BambergerBerlé fission has occurred during benzoylation. Since N-substituted iminazoles do not react with benzoyl chloride and alkali (Pinner \& Schwarz, 1902), $B$ cannot have structure (II); likewise the formation of formic acid and the isolation of (IV) excludes a seven-membered ring structure. 
<smiles>O=CCOC(=O)NCCc1cnc[nH]1</smiles><smiles>CC(NCc1nnc[nH]1)C(=O)O</smiles><smiles>CC(Cc1cncn1C)NC(=O)O</smiles><smiles>CCNCc1nnc[nH]1</smiles>

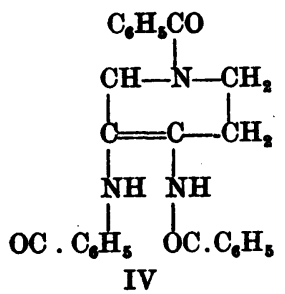

The compounds obtained from histidine by condensation with formaldehyde ate optically active; the decrease in laevo-rotation on addition of acid indicates, according 'to the criteria established by Lutz \& ,Jirgensons (1930), that the asymmetric centre in (I) has the l-configuration. It may, therefore, be designated $l(-) 1: 2: 5: 6$-tetrahydropyrido-3:4iminazole-6-carboxylic acid. Compound $A$ also has the tetrahydropyrido-iminazole structure, but the position of the labile methylol group is, however, uncertain; it may be situated at either of the two imino-nitrogens in (I), as shown in formulae (V) and (VI) respectively.<smiles>CC1CN(CO)C2CNCNC12N</smiles><smiles>O=C(O)C(CO)NCc1ncnn1CO</smiles>

Table 1. Apparent dissociation constants of histidine and of 1:2:5:6-tetrahydropyrido-3:4-iminazole-6carboxylic acid in the absence and presence of formaldehyde at $25^{\circ}$

The values for histidine are those of Levy (1935b), recalculated for $25^{\circ}$. The other values were obtained with solutions of an ionic strength of approximately $0 \cdot 08$. No extrapolation to zero ionic strength was made.

$\begin{array}{llll} & \text { Substance } & p K_{2} & p K_{3} \\ 1 & \text { Histidine } & 6 \cdot 12 & 9 \cdot 27 \\ 2 & \text { 1:2:5:6-Tetrahydropyrido-3:4- } & 4 \cdot 73 & 8 \cdot 58 \\ & \text { iminazole-6-carboxylic acid } & & \\ 3 & \text { Do. +1.05 mol. of formaldehyde } & 4 \cdot 56 & 8 \cdot 35 \\ 4 & \text { Do. +2.5 mol. of formaldehyde } & 4 \cdot 43 & 8 \cdot 21 \\ 5 & \text { Do. +20 mol. of formaldehyde } & 4 \cdot 15 & 7 \cdot 51\end{array}$

In view of the possibility that compounds $A$ and $B$ may be largely responsible for the behaviour of histidine under the conditions used in the Sorensen formaldehyde titration of amino-acids, the apparent dissociation constants of $B$ and the changes of these dissociation constants on addition of formaldehyde were determined. Table 1 gives the $p K$ values of the basic groups of histidine and of $B$. $p K_{2}$ corresponds to the ionization of the iminazole nucleus, whilst $p K_{3}$ is due to the ionization of the $\alpha$-amino group of histidine or of the tetrahydropyridine nitrogen of $B$. It can be seen that the $p K$ of the iminazole group has decreased in $B$ as compared with that of histidine by about 1.4 units; this is mainly due to the close proximity of the positively charged second imino group which is now separated from the iminazole nucleus by only one methylene group. The change in $p K_{3}$ is not quite so marked, being only about 0.7 unit; the decrease of this $p K$ may be due to the electronegative character of the double bond between $C_{4}$ and $C_{5}$ of the iminazole group having a greater effect in the tetrahydropyridine ring than in the open chain system of histidine.

On addition of increasing amounts of formalde. hyde, both $p K$ values decrease progressively, but the shift is greater in $p K_{3}$. These changes can be interpreted as indicating a reaction of both imino groups with the aldehyde; but it is also possible that formaldehyde combines only with one imino group and the change in the other $p K$ is due to the effect of the substitution of hydrogen by the electronegative methylol group on the other imino group. Potentiometric data do not enable us to decide between these two elternatives, but the fact that $A$ contains only one methylol group favours the second interpretation.

The optical rotations of $B$, its salts and that of the sodium salt of $A$ are very high compared with those of histidine and its salts ( $A$ itself is too insoluble to allow its rotation to be measured). Observation of changes of rotation with time appeared, therefore, to afford a convenient method of following the kinetics of the condensation. Fig. 1 shows the 
rotations observed over the first $48 \mathrm{hr}$. at different pH's. The values are not strictly comparable, since the rotations of both histidine and the condensation products vary with pH. It is clear, however, that the changes in rotation are very fast at $\mathrm{pH}$ values above 5.0. The speed does not increase appreciably on raising the $\mathrm{pH}$ from 7.4 to $11 \cdot 2$. Below $\mathrm{pH} 4.0$ the reaction is very slow. The final values which are obtained after 36-96 hr. agree within 5\% with slower increase which is not quite finished after $48 \mathrm{hr}$. This apparent slowing down of the reaction cannot be caused by a shift of $\mathrm{pH}$ occurring during the condensation, since it is also found in a buffered solution. Nor can it be due to slow depolymerization of formaldehyde or a fixation of formaldehyde by the reaction products, since the shape of the curve is not greatly affected by an increase in the proportion of the aldehyde. It is probable there are

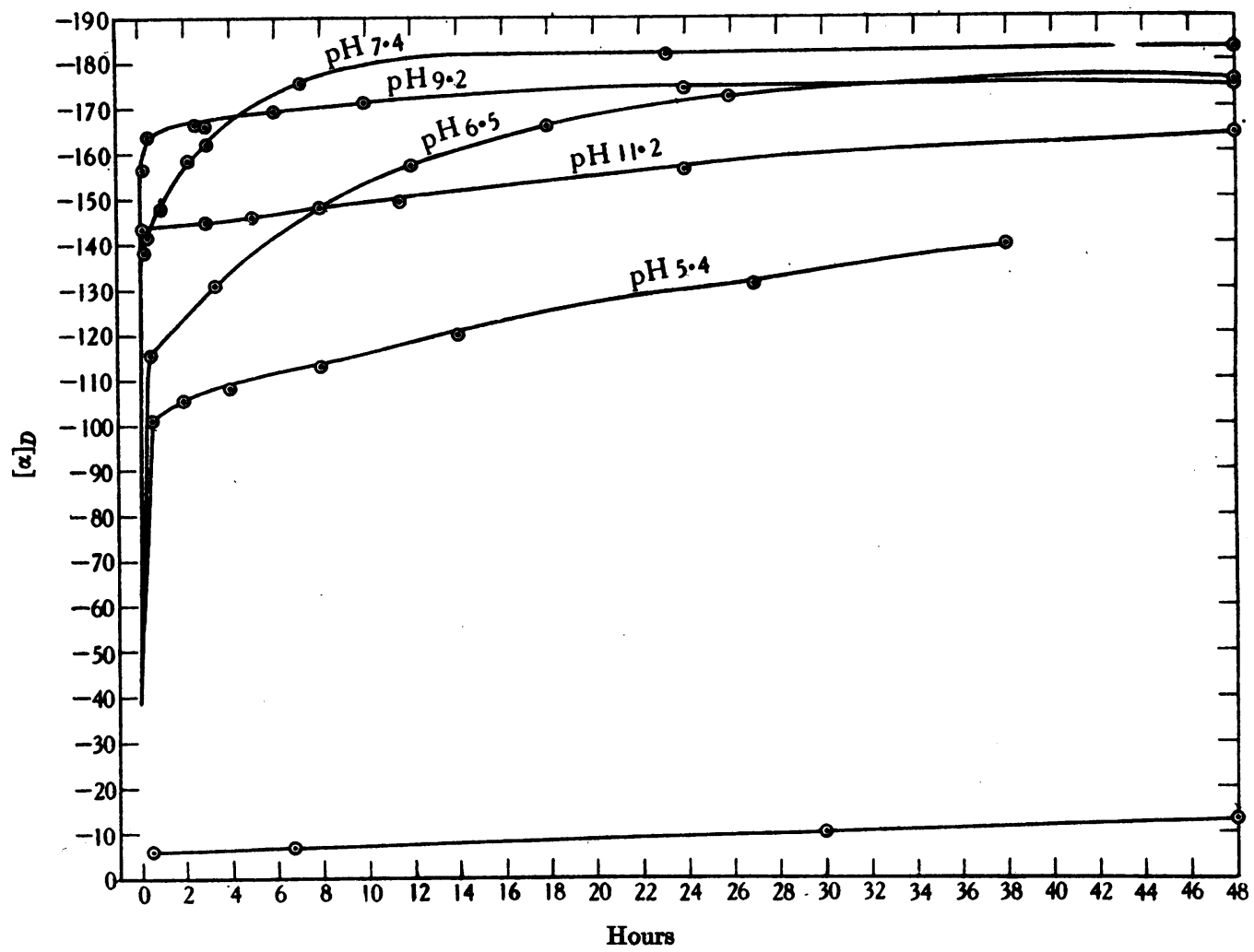

Fig. 1. Changes of optical rotation of equimolar mixtures of histidine and formaldehyde at different $\mathrm{pH}$ 's. The rotations are expressed in terms of $[\alpha]_{D}$ of histidine. The $\mathrm{pH}$ stated refers to the initial $\mathrm{pH}$ of the histidine-buffer mixture before formaldehyde was added. The required pH was obtained by adding the calculated amount of acid or alkali to the histidine solution, which was then mixed with the appropriate buffer; $0.2 \mathrm{M}$ acetate, phosphate and borate respectively were used. The molar concentration of the buffer greatly exceeded that of the histidine.

those calculated for the respective condensation products at the particular $\mathrm{pH}$ used. It might appear from this, and from tho fact that $A$ and $B$ respectively can be isolated in crystalline form from these mixtures after adjustment of $\mathrm{pH}$ to about $6 \cdot 6$, that the changes in rotation are simply a measure of a direct conversion of histidine to these two products, but closer inspection of the curves (Fig. 2) does not bear out this interpretation. The very rapid change which occurs in the first $3 \mathrm{~min}$. and which is equivalent at $\mathrm{pH} \mathbf{7 . 4}$ to about half the total change in rotation observed, is followed by a very much two reactions involved, a first fast reaction being followed by a much slower one, the latter leading to compounds $A$ and $B$. The failure to isolate $A$ and $B$ during the first few hours of the reaction, even after inoculation, supports this explanation. Wadsworth \& Pangborn (1936) drew the same conclusion that this reaction is a two-stage process from a comparison of the disappearance of amino- $\mathrm{N}$ and of free formaldehyde. They observed that, whilst loss of amino-N as measured by the nitrous acid method was very fast, as already found by Holden \& Freeman (1931), the disappearance of formaldehyde, 
as estimated by the dimedon method, was very much slower. They concluded that the initial product is more stable towards nitrous acid than towards dimedon. On the nature of the first reaction one can only speculate. It might be a Schiff's base or mono- or dimethylol compound formed by reaction with the $\alpha$-amino group. It would have to be assumed that the hypothetical intermediate, although unstable towards dimedon, is not split nitrous acid and hydrolyzed in the presence of dimedon, due to the reversible nature of this condensation (Titherley \& Branch, 1913). Such a rearrangement involving a migration from nitrogen to carbon would be similar to that postulated by Pauly (1915) in the coupling of iminazoles with diazonium selts.

The question naturally arises as to the relation of these results to those of the titration of histidine

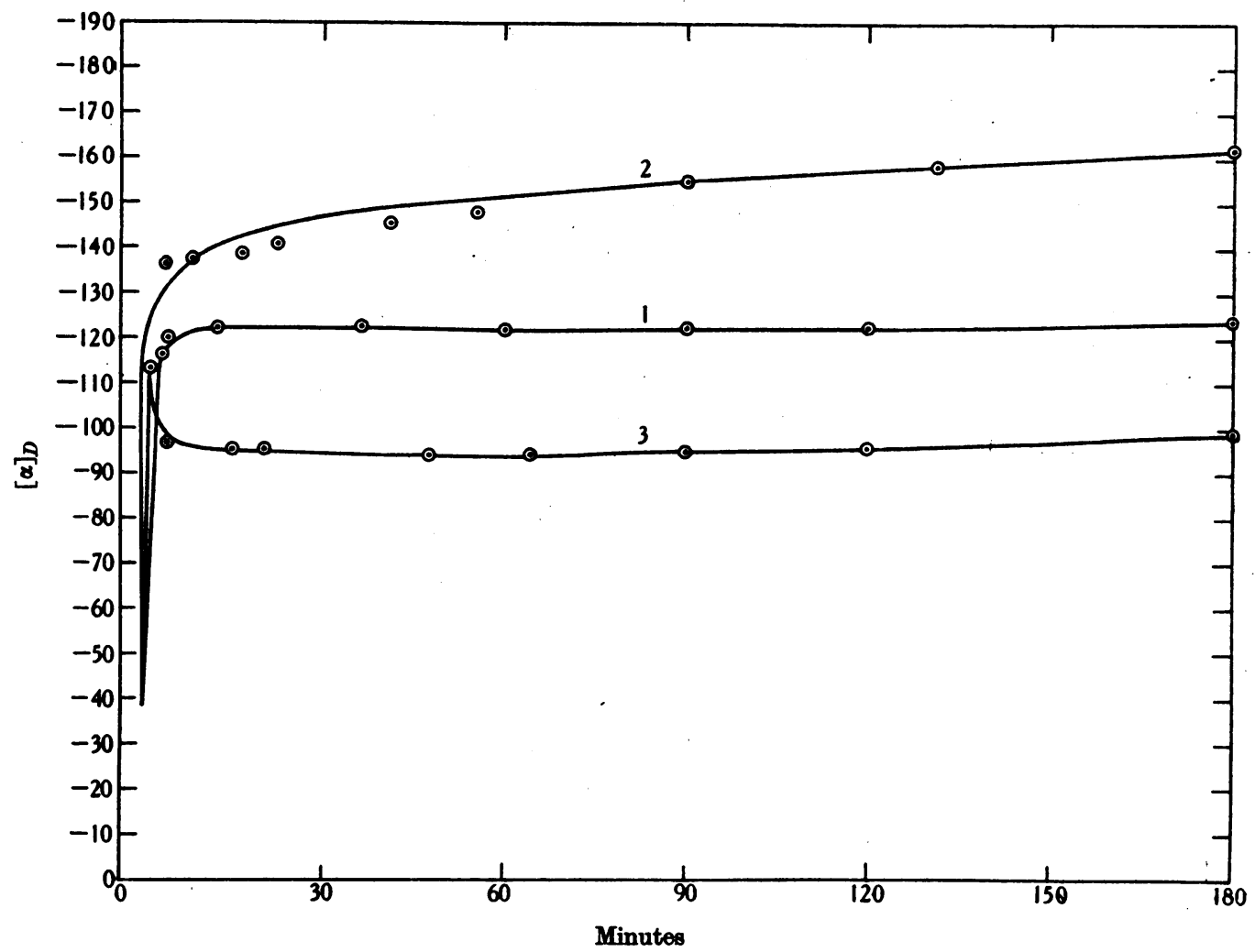

Fig. 2. Changes of rotation of mixtures of iscelectric histidine with 1 or 2 mol. of formaldehyde. Experimental details as in Fig. 1. Curve 1: $1 \mathrm{~mol}$. of formaldehyde, unbuffered. Curve 2: $1 \mathrm{~mol}$. of formaldehyde, phosphate buffer of pH 7.4. Curve 3: 2 mol. of formaldehyde, unbuffered.

under the acid conditions used.in the nitrous acid method. Such an assumption implies that the first reaction product differs in its stability from analogous formaldehyde derivatives of many other aminoacids which are easily split and give full amino-N values. It is possible that the positively charged iminazole group might stabilize somewhat an $\mathrm{N}$. methylol linkage, without affecting its reactivity with dimedon, although evidence on this point is lacking. Another possibility is that the initial product has the hexahydropyrimidine structure (II), which then rearranges itself to a tetrahydropyridine (I). It might be expected to be stable to by alkali in the presence of formaldehyde by the Sorensen method. A solution of histidine and formaldehyde shortly after mixing will contain, besides compound $A$ or $B$, a considerable proportion of the initial product whose existence, as pointed out above, is only inferred and whose nature is the subject of discussion. The titration data of Levy (1935a) suggest an initial cyclization, involving iminazole groups. As Levy $(1935 a)$ found, the $p K$ of iminazoles carrying no aliphatic amino group is not shifted by addition of formaldehyde, whilst in histidine the $p K$ values of both the amino and the iminazole groups are displaced by formaldehyde. 
Such displacement is most easily explained by assuming that the iminazole group is involved in the initial reaction.

The wide pH range, over which the reaction takes place, suggests that condensation does not depend on the amino group and probably not even on the iminazole group being uncharged. Acylation of the amino group, however, prevents condensation, since both $\alpha$-N-benzoyl and $\alpha-\mathrm{N}$-acetyl-histidine were recovered unchanged on prolonged incubation with excess of formaldehyde at $37^{\circ}$. The reaction investigated here cain, therefore, have no direct application to the interaction of formaldehyde with proteins, unless we assume that some of the $\alpha$-amino groups present in proteins are those of histidine, but it is possible that methylene bridges may be formed by formaldehyde between iminazole groups in proteins and neighbouring amino groups.

Another point must be mentioned. The rapid reaction of histidine with formoldehyde and possibly with other aldehydes may lead to errors in the estimation of $\beta$-hydroxy- $\alpha$-amino-acids by the periodate method, especially in the estimation of serine, which is based on the measurement of the formaldehyde evolved (Nicolet \& Shinn, 1939; Boyd \& Logan, 1942).

\section{EXPERIMENTAL}

All m.p.'s are uncorrected. Elementary micro-analyses were kindly carried out by Mr Parker.

All $\mathrm{pH}$ measurements were made at $25^{\circ} \pm 0 \cdot 1$ with a glass-electrode which had been standardized against phthalate and phosphate buffers.

Polarimetric measurements were carried out at concentrations of histidine varying between 1.9 and $2.1 \%$. The temperature varied between 18 and $21^{\circ}$.

Preparation of compound A from histidine. A mixture of $l(-)$-histidine $(3 \cdot 1 \mathrm{~g}$.$) dissolved in water (80 \mathrm{ml}$.) and $6 \mathrm{M}$ formaldehyde solution $\left(8.5 \mathrm{ml}\right.$.) was left at $37^{\circ}$ for $40 \mathrm{hr}$. The crystalline precipitate was filtered off and washed successively with water, ethanol and ether (yield, 95\%); it had m.p. $210-215^{\circ}$ (decomp.). The substance contains water of crystallization which is lost on drying at $100^{\circ} / 0 \cdot 1 \mathrm{~mm}$. (Found: C, 44.4; H, 6.2; N, 19.6; loss on drying, 8.3. $\mathrm{C}_{8} \mathrm{H}_{11} \mathrm{O}_{3} \mathrm{~N}_{3} . \mathrm{H}_{2} \mathrm{O}$ requires $\mathrm{C}, 44 \cdot 6 ; \mathrm{H}, 6 \cdot 1 ; \mathrm{N}, 19 \cdot 5 ; \mathrm{H}_{2} \mathrm{O}$, $8.4 \%$.) The dried material is very hygroscopic.

The substance is insoluble in cold water and in all the usual organic solvents. On heating in water it went into solution slowly, and a distinct smell of formaldehyde became noticeable; on cooling and standing, about $80 \%$ of the original material of m.p. $210-215^{\circ}$ crystallized out again. The substance dissolved on. addition of one equiv. of $\mathrm{HCl}$, with liberation of formaldehyde which could be precipitated as its dimedon derivative. On neutralizing of the acidified solution, a precipitate again appeared which was shown to be identical with the original material by crystalline form, m.p., N- and water-content. The substance also dissolved in alkali; a solution in $1 \cdot 1$ equiv. of $\mathrm{NaOH}$ had $[\alpha]_{D}=-84 \cdot 6^{\circ}$ ( $c=1 \cdot 6$ in terms of free base).

Pauly's reaction was positive, even when the alkaline solution of compound $A$ was added to the alkaline, diazo- tized solution of sulphanilic acid. The intensity of the colour was about equal to that given by an equimolar solution of histidine. The ninhydrin reaction was negative.

Preparation of compound B. (1) By hydrolysis of compound A. To a solution of compound $A(1 \cdot 2 \mathrm{~g}$.$) in water$ (50 ml.) contsining $2 \mathrm{~N}-\mathrm{HCl}(3 \mathrm{ml}$.), dimedon $(2.2 \mathrm{~g}$.$) dis-$ solved in warm water $(200 \mathrm{ml}$.) was added. The mixture was left for $48 \mathrm{hr}$. at room temperature. The precipitate of formaldehyde-dimedon compound which had,formed was collected and weighed. Recrystallized from ethanol it had m.p. $188-189^{\circ}$ undepressed by an authentic specimen. (Yield, $98 \%$ of theoretical for loss of $1 \mathrm{~mol}$. formaldehyde.) The mother liquor and washings were combined, neutralized exactly with $\mathrm{LiOH}$ and concentrated in vacuo. On addition of ethanol, large needles separated. (Yield, 60\%.) On recrystallization from a little water, m.p. was 277 . (Found: $\mathrm{C}, 41 \cdot 6 ; \mathrm{H}, 6 \cdot 3 ; \mathrm{N}, 20 \cdot 6$; loss on drying, 17.2. $\mathrm{C}_{7} \mathrm{H}_{2} \mathrm{O}_{2} \mathrm{~N}_{8} .2 \mathrm{H}_{2} \mathrm{O}$ requires $\mathrm{C}, 41.4 ; \mathrm{H}, 6.4 ; \mathrm{N}, 20.7 ; \mathrm{H}_{2} \mathrm{O}, 17.8 \%$.) The substance contained water of crystallization which could be remored by drying at $100 \% \cdot 1 \mathrm{~mm}$. The Pauly reaction was positive. The ninhydrin reaction and Knoop's bromine reaction were negative. The $[\alpha]_{D}$ values at different $\mathrm{pH}^{\prime} \mathrm{s}$ were as follows:

\begin{tabular}{lcc}
\multicolumn{1}{c}{ Addition } & {$[\alpha]_{D}$} & $\begin{array}{c}\text { Concentration } \\
(\%)\end{array}$ \\
- & $-144 \cdot 5^{\circ}$ & $\mathbf{2 \cdot 2}$ \\
1 equiv. $\mathrm{NaOH}$ & $-122 \cdot 4^{\circ}$ & $\mathbf{2 \cdot 1}$ \\
1 equiv. $\mathrm{HCl}$ & $-\mathbf{1 3 9 \cdot 7 ^ { \circ }}$ & $\mathbf{1 . 8 5}$ \\
2 equiv. $\mathrm{HCl}$ & $-\mathbf{1 2 1 \cdot 2 ^ { \circ }}$ & $\mathbf{1 . 6}$
\end{tabular}

(2) From histidine of $\mathrm{pH} 7 \cdot 45$. $l(-)$-Histidine (0.465 g.) dissolved in water $(10 \mathrm{ml}$.) was incubated with exactly 1 mol. of formaldehyde (3 ml. of $1 \mathrm{~N}$-solution) at $37^{\circ}$ for 2 days. The solution was then chilled to $0^{\circ}$ and the crystalline precipitate filtered off. It was recrystallized from aqueous ethanol and shown to be identical with compound $B$ by analysis and optical rotation.

(3) From histidine by condensation with methylal and conc. HCl. $l(-)$-Histidine monohydrochloride hydrate $(5.6 \mathrm{~g}$ ) was dissolved in conc. HCl (24 ml.) and the solution kept at $100^{\circ}$ for $3.5 \mathrm{hr}$., whilst methylal $(5 \mathrm{ml}$.) was slowly added through a dropping funnel. After having been kept at that temperature for a further $4 \mathrm{hr}$., the solution was evaporated in vacuo. The residue was taken up in water, the pH adjusted to 3.5 by addition of pyridine and ethanol was added. The precipitate was collected and recrystallized from aqueous ethanol; it had m.p. 279-280 . (Yield, $75 \%$.) (Found: C, 41.0; H, 5.1; N, 20.7; Cl, 17.3. $\mathrm{C}_{7} \mathrm{H}_{10} \mathrm{O}_{2} \mathrm{~N}_{3} \mathrm{Cl}$ requires $\mathrm{C}, 41.3 ; \mathrm{H}, 4.9 ; \mathrm{N}, 20.6 ; \mathrm{Cl}, 17.4 \%$.) The hydrochloride was converted into compound $B$ itself by exact neutralization of the concentrated aqueous solution with LiOH. The free base was identified by analysis, water content and optical rotation.

Conversion of compound B into A. Compound B (0.215 g.) was dissolved in water $(5 \mathrm{ml}$.) and $6 \mathrm{M}$-formaldehyde solution (0.25) was added. Large rod-like crystals appeared almost at once. The material had m.p. 210-215 and $[\alpha]_{D}=-85^{\circ} \quad(c=2.0$ in 1.1 equiv. of $\mathrm{NaOH})$. (Found: $\mathrm{N}$, 19.3; calc. for $\mathrm{C}_{8} \mathrm{H}_{18} \mathrm{O}_{4} \mathrm{~N}_{8}: \mathrm{N}, 19.5 \%$.) (Yield, $80 \%$.)

Attempted condensation of $\alpha-N$-benzoyl-histidine with formaldehyde. $\alpha-N$-Benzoyl-l( -)-histidine (8.13 g.) was dissolved in water $(100 \mathrm{ml}$.) containing $1.08 \%-\mathrm{LiOH}(27.2 \mathrm{ml}$.) and förmaldehyde (10 equiv.). The mixture was left at $37^{\circ}$ for 10 days. N-HCl (29 ml.) was then added. The solution was then concentrated in vacuo to dryness, the residue was dissolved in water and again concentrated. On addition 
$6.5 \mathrm{~g}$. of crystalline material were obtained which was found to be unchanged hydrate of benzoyl-histidine. It had m.p. $245^{\circ}$ (decomp.) and $[\alpha]_{D}=-47 \cdot 1^{\circ}(c=2 \cdot 1)$. The authentic specimen had m.p. $247^{\circ}$ (decomp.) and $[\alpha]_{D}=-47.3^{\circ}$ $(c=2 \cdot 2)$.

Decarboxylation of compound B to 1:2:5:6-tetrahydropyrido3:4-iminazole. Compound $B$ (1.5 g.) was heated to $130^{\circ}$ until all the water of crystallization had been removed and was mixed with $4.5 \mathrm{~g}$. of melted fluorene. The mixture was then slowly heated to $265^{\circ}$ and kept between $265^{\circ}$ and $270^{\circ}$ for $30 \mathrm{~min}$. The mixture was cooled, extracted twice with $15 \mathrm{ml} .2 \mathrm{~N}-\mathrm{HCl}$, the acid solution extracted with ether and then made strongly alkaline by addition of $10 \mathrm{~N}-\mathrm{NaOH}$. The alkaline solution was extracted with amyl alcohol (150 ml.) in three portions, the combined alcoholic extracts dried over $\mathrm{Na}_{2} \mathrm{SO}_{4}$, filtered and extracted five times with N-HCl. The combined acid extracts were evaporated in vacuo and the residue recrystallized twice from $95 \%$ aqueous ethanol. It amounted to $35 \mathrm{mg}$. and had m.p. 276-277 . A specimen mixed with material prepared from histamine (Dale \& Dudley, 1921) showed no depression. (Found: $\mathrm{N}, 21 \cdot 2$. Calc. for $\mathrm{C}_{6} \mathrm{H}_{11} \mathrm{~N}_{2} \mathrm{Cl}_{2}: \mathrm{N}, 21 \cdot 47 \%$.) $25 \mathrm{mg}$ : were converted into the picrate, which gave m.p. 212-214 alone or mixed with the dipicrate of the product from histamine.

Preparation of 3:4-dibenzamido-N-benzoyl-1:2:5:6-tetrahydropyridine. 1:2:5:6-Tetrahydropyrido-3:4-iminazole (0.9g.) prepared from histamine (Dale \& Dudley, 1921) was dissolved in $\mathrm{N}-\mathrm{NaOH}(10 \mathrm{ml}$.) and benzoylated with benzoylchloride (4 g.) and $2 \mathrm{~N}-\mathrm{NaOH}(16 \mathrm{ml}$.) in the usual way. The oil which formed during the reaction was extracted with chloroform; the extract washed successively with $\mathrm{N}-\mathrm{NaOH}$, water and $2 \mathrm{~N}-\mathrm{HCl}$, dried and evaporated in vacuo. Twice crystallized from $60 \%$ aqueous ethanol, the product had m.p. 215 ${ }^{\circ}$. (Yield, 25\%.) (Found: C, 73.2; H, 5.2; $\mathrm{N}, 10 \cdot 1$. Calc. for $\mathrm{C}_{26} \mathrm{H}_{23} \mathrm{O}_{3} \mathrm{~N}_{3}: \mathrm{C}, 73.4 ; \mathrm{H}, 5.4 ; \mathrm{N}, 9.9 \%$.)

The mother liquor from the benzoylation was acidified and most of the benzoic acid removed by filtration. The solution was then steam-distilled. The distillate was made just alkaline with $\mathrm{NaOH}$ and concentrated to small volumè. The residue was then acidified with $\mathrm{H}_{2} \mathrm{SO}_{4}$ and again distilled. The distillate was strongly acid, although apparently free from $\mathrm{H}_{4} \mathrm{SO}_{4}$, and reduced $\mathrm{AgNO}_{3}$ under acid conditions.

\section{SUMMARY}

1. It is shown that histidine reacts with one mol. of formaldehyde to give a tetrahydropyrido-iminazole carboxylic acid. The structure of this acid has been demonstrated by decarboxylation followed by a . Bamberger-Berlé fission. In presence. of excess formaldehyde a very insoluble methylol derivative of this product is obtained.

2. The dissociation constants of the two compounds have been measured and compared with those of histidine.

3. The kinetics of the reaction have been examined and the bearing of the results on the formaldehyde titration of histidine been discussed.

\title{
REFERENCES
}

Birch, T. W. \& Harris, L. J. (1930). Biochem. J. 24, 1080. Boyd, M. J. \& Logan, M. L. (1942). J. biol. Chem. 146, 279. Burian, R. (1904). Ber. dtsch. chem. Ges. 87, 696.

Dale, H. H. \& Dudley, H. W. (1921). J. Pharmacol. 18, 103. Fargher, R. G. \& Pyman, F. L. (1919). J. chem. Soc. $115,217$.

Fraenkel, S. \& Zeimer, K. (1920). Biochem. Z. 110, 234.

Frieden, E., Dunn, M. S. \& Coryell, C. O. (1943). J. phys. Chem. 47, 85.

Holden, H. F. \& Freeman, M. (1931). Aust. J. exp. Biol. med. Sci. 8, 189.

Lovy, M. (1935a). J. biol. Chem. 109, 365. (1935b). J. biol. Chem. 109, 361. \& Silbermann, D. E. (1937). J. biol. Chem. 118, 723.
Lutz, O. \& Jirgensons, B. (1930). Ber. dtsch. chem. Ges. 63, 448.

Nicolet, B. H. \& Shinn, L. A. (1939). J. biol. Chem. 139, 687.

Pauly, H. (1915). Hoppe-Seyl. Z. 94, 284.

Pinner, A. \& Schwarz, R. (1902). Ber. dtsch. chem. Ges. 35, 2441.

Schiff, H. (1900). Liebigs Ann. 310, 25.

Titherley, A. W. \& Branch, G. E. (1913). J. chem. Soc. $103,330$.

Wadsworth, A. \& Pangborn, M. C. (1936). J. biol. Chem. 116, 423.

Waser, E. (1925). Helv. chim. Acta, 8, 758.

Wellisch, J. (1913). Biochem. Z. 49, 173.

\section{The Microbiological Assay of Nicotinic Acid in Cereals and Other Products}

\author{
By E. C. BARTON-WRIGHT, The Cereals Research Station, Ministry of Food, St Albans
}

(Received 10 July 1944)

We have had difficulty in the assay of nicotinic acid in cereals and cereal products by the chemical method described by Kodicek (1940), owing to the presence of interfering substances. On the other hand, the microbiological method originally introduced by Snell \& Wright (1941), later modified by
Krehl, Strong \& Elvehjem (1943), and now further modified, has been found to be expeditious and accurate.

The chief drawback to the Snell \& Wright method as originally published was the non-linearity of the standard curve with concentrations of nicotinic acid 